\title{
The influence of radiotherapy techniques on the plan quality and on the risk of secondary tumors in patients with pituitary adenoma
}

Marius Treutwein ${ }^{1 *} \mathbb{D}$, Felix Steger ${ }^{1}$, Rainer Loeschel ${ }^{2}$, Oliver Koelbl ${ }^{1}$ and Barbara Dobler ${ }^{1}$

\begin{abstract}
Background: This planning study compares different radiotherapy techniques for patients with pituitary adenoma, including flatness filter free mode (FFF), concerning plan quality and secondary malignancies for potentially young patients. The flatness filter has been described as main source of photon scatter.

Material and methods: Eleven patients with pituitary adenoma were included. An Elekta Synergy ${ }^{\mathrm{TM}}$ linac was used in the treatment planning system Oncentra ${ }^{\circledR}$ and for the measurements. 3D plans, IMRT, and VMAT plans and noncoplanar varieties were considered. The plan quality was evaluated regarding homogeneity, conformity, delivery time and dose to the organs at risk. The secondary malignancy risk was calculated from dose volume data and from measured dose to the periphery using different models for carcinoma and sarcoma risk.
\end{abstract}

Results: The homogeneity and conformity were nearly unchanged with and without flattening filter, neither was the delivery time found substantively different. VMAT plans were more homogenous, conformal and faster in delivery than IMRT plans. The secondary cancer risk was reduced with FFF both in the treated region and in the periphery. VMAT plans resulted in a higher secondary brain cancer risk than IMRT plans, but the risk for secondary peripheral cancer was reduced. Secondary sarcoma risk plays a minor role. No advantage was found for non-coplanar techniques. The FFF delivery times were not shortened due to additional monitor units needed and technical limitations. The risk for secondary brain cancer seems to depend on the irradiated volume. Secondary sarcoma risk is much smaller than carcinoma risk in accordance to the results of the atomic bomb survivors. The reduction of the peripheral dose and resulting secondary malignancy risk for FFF is statistically significant. However, it is negligible in comparison to the risk in the treated region.

Conclusion: Treatments with FFF can reduce secondary malignancy risk while retaining similar quality as with flattening filter and should be preferred. VMAT plans show the best plan quality combined with lowest peripheral secondary malignancy risk, but highest level of second brain cancer risk. Taking this into account VMAT FFF seems the most advantageous technique for the treatment of pituitary adenomas with the given equipment.

Keywords: Pituitary adenoma, Treatment planning, Secondary malignoma risk, Flattening filter free

\footnotetext{
* Correspondence: marius.treutwein@ukr.de

${ }^{1}$ Department for radiotherapy, Regensburg University Medical Center,

Regensburg, Germany

Full list of author information is available at the end of the article
}

(c) The Author(s). 2020 Open Access This article is distributed under the terms of the Creative Commons Attribution 4.0 International License (http://creativecommons.org/licenses/by/4.0/), which permits unrestricted use, distribution, and reproduction in any medium, provided you give appropriate credit to the original author(s) and the source, provide a link to the Creative Commons license, and indicate if changes were made. The Creative Commons Public Domain Dedication waiver (http://creativecommons.org/publicdomain/zero/1.0/) applies to the data made available in this article, unless otherwise stated. 


\section{Background}

Radiotherapy of pituitary adenomas is often applied as postoperative therapy of tumors that cannot be removed completely. For over one decade patients with pituitary adenoma have been treated primarily with two parallel opposed fields or a three field technique [1-7]. Only a few recent publications describe the application of intensity modulated radiotherapy (IMRT) or volumetric modulated arc (VMAT) technique in this region [8-10], none of them mentioning the flatness filter free (FFF) mode. FFF is applicable in combination with fluence modulating techniques like IMRT or VMAT. In this mode a considerably higher dose rate is achieved by omitting the flatness filter. This planning study compares different plans for patients with pituitary adenoma. The plans were optimized using both modes: flattened beam (FB) and FFF. The flatness filter has been described as the main source of photon scatter in the treatment head [11]. Additional peripheral dose resulting from this contribution has been confirmed in some publications referring to other entities [12-18] and increases the risk for secondary malignancies. Pituitary adenomas represent about $10 \%$ of all intracranial tumors [19]. The incidence increases over the years, starting at about an age of 10 years and has a possible decline in high age [20]. Therefore, the risk for secondary malignancies should be considered. The aim of this study is to evaluate statistically significant differences for FB and FFF plans regarding the plan quality and the risk for secondary malignancies in the treated region and the periphery. Plans with two and three fixed beams were taken as reference.

\section{Material and methods Patients}

Data sets of 11 patients (five female, six male) with pituitary adenoma were used for this retrospective planning study. All patients have got a cranial X-ray CT scan in supine positioning with the head in neutral position. The head was immobilized using thermoplastic mask systems. The CT scans were fused with the pretherapeutic cranial MRI (contrast enhanced T1-weighted sequence). GTV, CTV and PTV as well as organs at risk were delineated using the treatment planning system (TPS) Oncentra ${ }^{\circledR}$ External Beam v4.5 (Nucletron ${ }^{\circ}$, an Elekta company) on all axial slices. The GTV included the macroscopic (residual) tumor volume. The CTV was based on GTV extended for the resection cavity in postoperative cases. The PTV was defined by CTV plus an isotropic margin of $3-5 \mathrm{~mm}$, depending on setup error and reproducibility of positioning.

\section{Linear accelerator}

We used a linear accelerator (linac) of type Elekta Synergy $^{\text {TM }}$ with Agility ${ }^{\text {ma }}$ head (Elekta AB, Stockholm, Sweden) operated by the desktop software Integrity 3.1 and record and verify system Mosaiq 2.50 . The head is equipped with
80 interdigitating leaf pairs, projecting a leaf width of $5 \mathrm{~mm}$ to the isocenter. For all plans $6 \mathrm{MV}$ photons were used. The beam quality of both modes FB and FFF has been shown to be equivalent for this machine type [21, 22]. The linac offers a maximum dose rate of $550 \mathrm{MU}$ per minute in FB mode and $1700 \mathrm{MU}$ per minute in FFF.

\section{Treatment planning}

The planning was performed with TPS Oncentra ${ }^{\bullet}$ External Beam using the collapsed cone algorithm. A grid size of $2 \mathrm{~mm}$ has been chosen. Variable gantry speed with a set maximum value of 6.0 degree per second is supported by the software. The variable dose rate was set to a minimum value of $20 \mathrm{MU}$ per minute. A dynamic and static minimum leaf gap of $1.0 \mathrm{~cm}$ had to be observed. The optimizer module in Oncentra ${ }^{\oplus}$ used the step-andshoot algorithm for IMRT optimizations [23]. This module has been developed by RaySearch Laboratories (Stockholm, Sweden) and therefore has the same roots as the SmartArc module in Pinnacle ${ }^{3}$ TPS (Philips, Amsterdam, Netherlands) and the proprietary development RayArc module in RayStation TPS.

The objectives for the PTV were set to a minimum dose of $49.4 \mathrm{~Gy}$ and a maximum dose of $51.4 \mathrm{~Gy}$ in 28 fractions, aiming for a fraction dose of $1.8 \mathrm{~Gy}$. A uniform dose objective to 50.4 Gy was added to improve the homogeneity. Further objectives were set for the following organs at risk (OAR) (Table 1) according to [24-26]: brain, brainstem, chiasm, both lenses, bulbs, lacrimal glands, and parotids. Additionally, the surrounding dose fall-off objective has been applied to shape the dose gradient from the PTV into the normal tissue [27]. It supports an improvement of the conformity. The same set of dose volume objectives has been used for all plans to get comparable results $[12,18$, $28,29]$. The aim of this set was to keep the risk for the OARs on an acceptable level, but to leave freedom for the optimizer to achieve good conformity and homogeneity. In both modes (FB and FFF) IMRT plans with nine equispaced coplanar fields were generated; in a second variant a tenth non-coplanar field was added. Similarly two different VMAT plans were optimized: one single arc rotation $\left(182^{\circ}-178^{\circ}\right)$, and the second with an added half rotation in the sagittal patient plane $\left(0^{\circ}-180^{\circ}\right)$.

The average dose to the PTV was set to $100 \%$ after the optimization process. An average dose value in a range of $50.4 \mathrm{~Gy} \pm 0.8 \mathrm{~Gy}$ - which represents an interval of about $1.5 \%$ around the target value - was accepted in the sense of a dose prescription according to ICRU 83 [30]. No rescaling has been performed as this would have affected the dose to the normal tissue and organs at risk which are also part of the optimization process [31]. 
Table 1 Treatment planning objectives

\begin{tabular}{lllll}
\hline Regions of interest & Dose level in Gy & Volume in \% & Dose volume objective type & Weight \\
\hline Brain & 20 & 20 & Maximum dose volume & 300 \\
& 30 & 10 & Maximum dose volume & 300 \\
& 40 & 5 & Maximum dose volume & 300 \\
Brainstem & 51.4 & 0 & Maximum dose & 500 \\
Chiasm & 50 & 0 & Maximum dose & 300 \\
Lens & 15 & 0 & Maximum dose & 30 \\
Bulb & 35 & 50 & Maximum dose volume & 100 \\
Lacrimal gland & 20 & 50 & Maximum dose volume & 30 \\
Parotid & 30 & 50 & Maximum dose volume & 100 \\
Outline & 51.4 & 0 & Maximum dose & 3000 \\
& $49.4-25.0$ & & Surrounding dose falloff, distance $1 \mathrm{~cm}$ & 3000 \\
PTV & 49.9 & 100 & Minimum dose & 3000 \\
& 51.4 & 0 & Maximum dose & 3000 \\
& 50.4 & & Uniform dose & 1000 \\
\hline
\end{tabular}

\section{Plan evaluation}

The following parameters were evaluated: the average dose to the PTV ${ }_{\text {av }}{ }^{\text {PTV }}$, homogeneity index HI, and the conformity index CI. For HI the definition of ICRU report 83 [30] was used: $\mathrm{HI}=\left(\mathrm{D}_{2 \%}{ }^{\mathrm{PTV}}-\mathrm{D}_{98 \%}{ }^{\mathrm{PTV}}\right) / \mathrm{D}_{\mathrm{av}}{ }^{\mathrm{PTV}}$ with $\mathrm{D}_{2 \%}{ }^{\text {PTV }}$ and $\mathrm{D}_{98 \%}{ }^{\text {PTV }}$ as dose to 2 and $98 \%$ of the PTV. CI was defined according to Paddick [32]: $\mathrm{CI}=$ $\mathrm{TV}_{49.4 \mathrm{~Gy}^{2}}{ }^{2}\left(\mathrm{~V}_{49.4}\right.$ Gy $\left.\mathrm{x} \mathrm{V}^{\mathrm{PTV}}\right)$. $\mathrm{TV}_{49.4 \text { Gy }}$ is the volume within the PTV which receives at least $49.4 \mathrm{~Gy}, \mathrm{~V}_{49.4 \text { Gy }}$ is the volume enclosed by the corresponding isodose within the complete patient contour, and $\mathrm{V}^{\mathrm{PTV}}$ is the volume of the PTV. For all plans the observance of the objectives for the OAR was investigated and regarded as criterion of acceptability.

\section{Measurements}

The evaluation of the peripheral dose (PD) was performed using the upper part of a male Alderson phantom (RSD Inc., Long Beach, CA, USA) (Fig. 1). Two slabs of the phantom were replaced by copies of PA material with bores for ionization chambers. The first chamber in a distance of $16.3 \mathrm{~cm}$ from isocenter corresponded to the position of the thyroid gland, the second in a distance of $30.3 \mathrm{~cm}$ in the upper thoracic region corresponded to an esophageal position. The dose to these points, $\mathrm{PD}^{\text {thyr }}$ and $\mathrm{PD}^{\text {esoph }}$ has been measured with chambers type M30016 $\left(0.3 \mathrm{~cm}^{3}\right)$ and M23331 $\left(1.0 \mathrm{~cm}^{3}\right)$, respectively, both connected to Unidos dosimeters (PTW, Freiburg, Germany). It is reasonable to assume an uncertainty of $5 \%$ for these

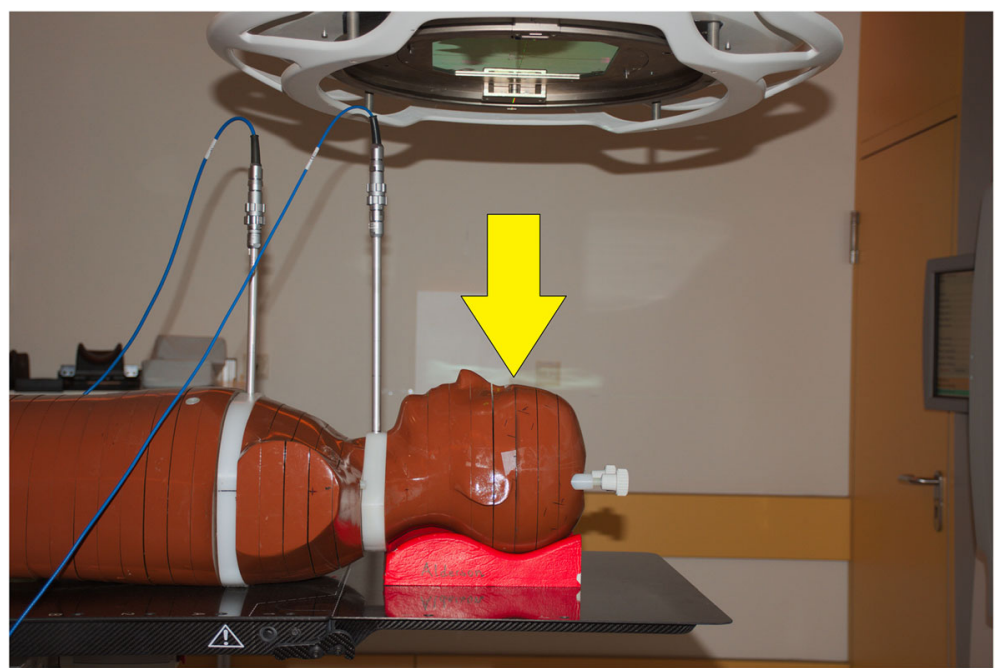

Fig. 1 Setup of the Alderson phantom for the peripheral dose measurements. The ionization chambers are inserted in the white slabs. The arrow indicates the isocenter plane 
measurements considering the statistical uncertainty, the positioning inaccuracy and the calibration of the detector for megavoltage beam quality [33].

The plan verifications were accomplished with the SRS MapCHECK $^{\mathrm{Tx}}$ array and StereoPHAN ${ }^{\mathrm{m}}$ phantom equipment (Fig. 2) in combination with the SNS Patient ${ }^{\mathrm{Tm}}$ software version 8.1 (Sun Nuclear Corporation, Melbourne, FL, USA). The array is a rather new developed device. Its size is $77 \times 77 \mathrm{~mm}^{2}$, the diodes have a spacing of $2.47 \mathrm{~mm}$. The active detector area is $0.48 \times 0.48 \mathrm{~mm}^{2}$. The signals are sampled with a frequency of $20 \mathrm{~Hz}$. Gantry angles are analyzed by the angular dependency of two opposing detector planes. Therefore, no gantry angle sensor is necessary. The phantom has already been used with other modular inserts for films [34] and ionization chambers. The system is especially designed for small volumes.

We applied a hybrid plan verification as described for other systems [35-37] transferring the patient plan unchanged to the phantom and performing a dose calculation on the phantom with a dose grid of $1 \mathrm{~mm}$. A CT scan of the phantom has been offered by the manufacturer, slices in $1 \mathrm{~mm}$ distance; a uniform relative mass density of 1.2 has been assigned to the external structure as recommended. The array was positioned horizontally in the isocenter plane.

The software assists a cross-calibration procedure. Offered shifts of the measured profiles relative to the calculated ones for best coincidence were accepted, but were clearly smaller than $1.0 \mathrm{~mm}$. The measured and calculated dose distributions were evaluated by the gamma index [38] with a dose tolerance of $3 \%$ referring to the maximum dose and a distance to agreement of $3 \mathrm{~mm}$. The area of the evaluation was confined to dose values above $10 \%$ of the dose maximum [39].
As an additional plan quality parameter the delivery time (DT) was recorded from pressing the beam on button until the last beam off.

\section{Secondary malignancy risk}

The calculations for the risk of secondary malignancies use the models presented by Schneider et al. [40]. Their work combines the data of the Japanese A-bomb survivors [41] and secondary cancer data of Hodgkin's patients from a Western population [42]. The excess absolute risk (EAR) describes the risk of malignancy incidence after irradiation. It is expressed as absolute difference of the number of malignancies in comparison to an untreated control group. Commonly it is given per 10.000 persons per year. It is a function of the dose $d$, the sex $s$, the age at exposure $e$ and the attained age $a$.

$$
\operatorname{EAR}(d, s, e, a)=\mu(s, e, a) \times f(d)
$$

In the present work gender averaged values are used. Therefore, the parameter $s$ can be neglected. Using the tables given in [40], the EAR can be calculated from the dose volume data from the TPS for different organs of volume $\mathrm{V}_{\mathrm{T}}$ :

$$
\begin{aligned}
E A R^{\text {org }}= & \frac{1}{V_{T}} \sum_{i} V\left(D_{i}\right) \times \beta_{E A R} \times R E D\left(D_{i}\right) \\
& \times \mu(e, a)
\end{aligned}
$$

The summation is performed over all voxels of the organ with dose entry $D_{i}$. $\mu$ can be used to calculate the risk for different ages (e: age at exposition, $a$ : attained age):

$$
\mu(e, a)=\exp \left(\gamma_{e}(e-30)+\gamma_{a} \ln \left(\frac{a}{70}\right)\right)
$$

The parameters $\gamma_{e}$ and $\gamma_{a}$ were derived by Preston et al. [41]. For our calculations we have chosen $e=35$ years,

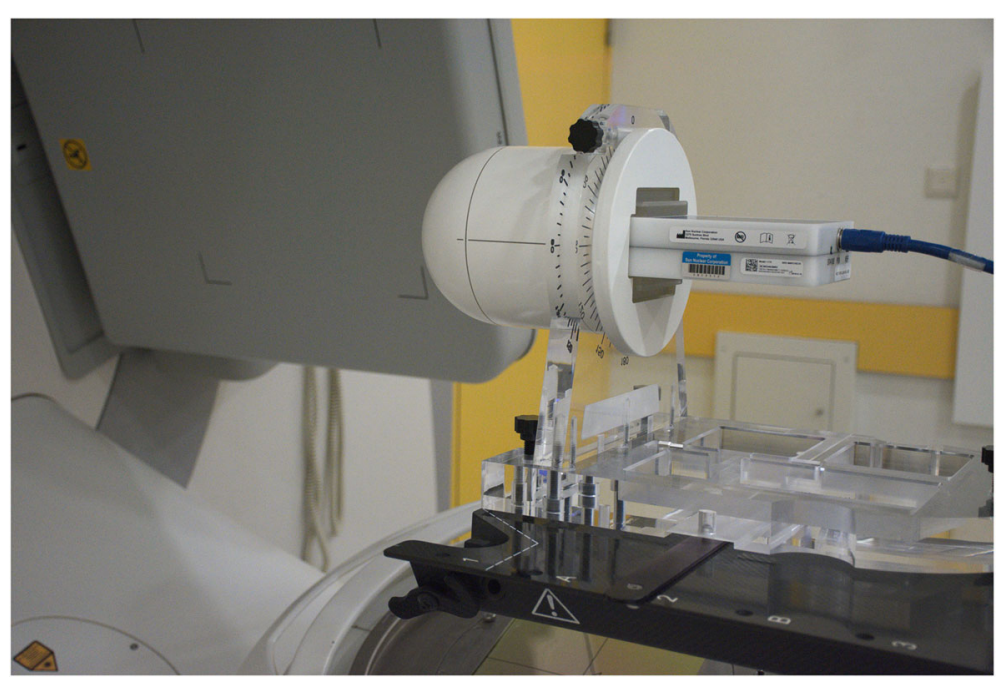

Fig. 2 Setup for the plan verification with SRS MapCHECK ${ }^{\mathrm{TM}}$ array inserted in the StereoPHAN ${ }^{\mathrm{TM}}$ phantom 
which is close to the mean age given by Yamanaka et al. [43] (37 years) and corresponds to the mean age minus one standard deviation by Jiang et al. [44]. The attained age was set to $a=70$ years.

$\beta_{E A R}$ is the initial slope, the risk equivalent dose $R E D$ the dose dependent part, for which Schneider et al. present different models for carcinoma induction:

- The mechanistic model which considers cell killing and fractionation effects

- The bell-shaped dose response model which neglects any repopulation or repair effect

- The plateau model with full repopulation or repair

The mechanistic model is given by the form

$$
R E D(D)=\frac{e^{-\alpha^{\prime} D}}{\alpha^{\prime} R}\left(1-2 R+R^{2} e^{\alpha^{\prime} D}-(1-R)^{2} e^{\frac{\alpha^{\prime} R}{1-R} D}\right)
$$

assuming a fractionated treatment schedule of single fractions with dose $d$ up to a total dose $D . \alpha^{\prime}$ has been derived from the linear quadratic model, assuming $\alpha /$ $\beta=3$ Gy for all tissues.

$$
\alpha^{\prime}=\alpha+\beta d
$$

$R$ is the repopulation and repair parameter and equals 0 for no and 1 for full repair or repopulation. The bellshaped model is got in the limit of $R$ to 0 :

$$
R E D(D)=D e^{-\alpha^{\prime} D}
$$

In the limit of $\mathrm{R}$ to 1 the plateau model is described:

$$
R E D(D)=\left(1-e^{-\alpha^{\prime} D}\right) / \alpha^{\prime}
$$

The authors emphasize that there is only little knowledge yet about the dose-response relationships in the investigated dose range [40]. The data could not be fitted by all models for all organs, not even the most complex mechanistic model. Therefore, we performed our calculations for all three models.

At last we also applied the model for sarcoma induction of bone and soft tissue. The formula is quite similar to the mechanistic model for carcinoma induction with one additional term:

$$
R E D(D)=\frac{e^{-\alpha^{\prime} D}}{\alpha^{\prime} R}\left(1-2 R+R^{2} e^{\alpha^{\prime} D}-(1-R)^{2} e^{\frac{\alpha^{\prime} R}{1-R} D}-\alpha^{\prime} R D\right)
$$

We confined our calculations to an intermediate repopulation and repair effect with $R=0.5 . \beta_{E A R}, \gamma_{e}$, and $\gamma_{a}$ are given in Table 2 for the investigated organs.

The two peripheral dose points were situated in the low dose region. It has been shown by Preston et al. [41] that for these points up to a total dose of 2 Gy the simple linear model is applicable.
Table 2 Initial slope and age modifying parameters for EAR calculation [40]

\begin{tabular}{llll}
\hline Organ at risk & $\beta_{\text {EAR }}$ & $\gamma_{e}$ & $\gamma_{a}$ \\
\hline Brain & 0.51 & -0.024 & 2.38 \\
Soft Tissue & 0.60 & -0.013 & -0.56 \\
Bone & 0.20 & -0.013 & -0.56 \\
Thyroid & - & -0.046 & 0.6 \\
\hline
\end{tabular}

$$
E A R^{o r g}=\beta_{E A R} \times D \times \mu(e, a)
$$

The factors $\beta_{E A R}$ for the selected OAR were taken from this publication and applied according [40]. They are given per 10.000 persons per year and Gy as 1.2 for the thyroid gland and 0.58 for the esophagus. For the esophagus no age dependency has been found. The age correction factor $\mu(e, a)$ for secondary cancer risk in the thyroid gland was calculated with $\gamma_{e}$ and $\gamma_{a}$ from Table 2. For this calculation the measured point dose has been taken representative for the whole organ.

\section{Statistics}

An a priori power analysis has been performed to determine the sample size using the software $G^{*}$ Power version 3.1.9.2 [45, 46]. We set $\alpha=0.05$, power $(1-\beta)=0.8$, and the effect size to 1.0. The Wilcoxon signed-rank test for paired samples was chosen as statistical test, as it does not require a normal distribution of the variables. Taking various parent distributions into account (normal, Laplace, logistic) the maximum sample size of $N=$ 11 for a normal distribution was selected.

$\mathrm{IBM}^{\circ} \mathrm{SPSS}^{\circ}$ Statistics v23 (IBM Corporation, Armonk, NY, USA) was applied to perform the Wilcoxon test with a significance level of 0.05 . The Bonferroni-Holm method was used to control the maximum experimentwise error rate for multiple testing [47]. Five variables were considered in this process: $\mathrm{HI}, \mathrm{CI}, \mathrm{DT}$, the sum of all calculated EAR from the dose volume histograms $\mathrm{EAR}_{\text {sum }}{ }^{\text {plan }}$, and the sum of the EAR calculated from the PD measurements EAR $_{\text {sum }}{ }^{\text {PD }}$. Differences in the application of VMAT and IMRT were investigated secondary with a significance level of 0.05 without corrections for multiple testing.

\section{Results}

Plan quality

Nearly all plans ended the optimization process with an average dose in the PTV in the required interval as described in the section "treatment planning" in material and methods. Only one plan (VMAT FB) failed 0.2 Gy below the required minimum value. All other treatment plan objectives have been met in all plans except of the chiasm. This objective has slightly been violated by nearly all plans as the chiasm has been part of the PTV. 
The maximum value of $\mathrm{D}_{2 \%}{ }^{\text {Chiasm }}$ was $1.7 \%$ above the limit in Table 1. Fig. 3 demonstrates the dose distribution of all calculated plans in the isocenter plane for one representative patient.

Fig. 4 shows the indexes $\mathrm{HI}$ and $\mathrm{CI}$. No statistically significant difference has been found for FB and FFF. HI is equivalent for the classical 2Fd and 3Fd techniques and all IMRT plans, but significantly improved for all VMAT plans. CI is lowest for 2Fd plans, shows all IMRT variants on one level and all VMAT variants again improved on a significantly higher level.

In Fig. 5 the delivery time DT is presented for the coplanar plans. For IMRT the difference of FB and FFF is not significant, for VMAT the FFF mode needs statistically significant more time. However, the difference is small $(7 \mathrm{~s})$. VMAT takes about the same time as two opposing fields (2Fd) and is faster than 3Fd and takes less than half the time of IMRT. The non-coplanar plans have not been evaluated in detail. Sample measurements have shown that for our local conditions nearly 2 mins additional time are required to enter the treatment room and arrange gantry and table position.

\section{Secondary malignancy risk}

Fig. 6 illustrates the EAR for secondary brain cancer depending on the technique and mode for the mechanistic model. The other two models are not shown in the figure to gain more clarity. For fluence modulating techniques the values for the bell-shaped model were about $10 \%$ higher, for the plateau model about $8 \%$ higher than for the mechanistic model. For the $2 \mathrm{Fd}$ and the $3 \mathrm{Fd}$ technique the differences between the models were up to $19 \%$, but again the bell-shaped model above the plateau model. The reduction of EAR by application of FFF instead of FB is statistically significant. Although the difference between both groups is very small, the significance of the statistics can be explained by the pairing of the samples in the Wilcoxon test: for all 11 pairings, the value for FFF was lower than for FB. The lowest risk is achieved by the simplest technique (2Fd). The differences between the three models are small. The noncoplanar techniques IMRT10 and VMAT2 create a higher risk than the coplanar techniques.

Fig. $7 \mathrm{a}$ and $\mathrm{b}$ show the EAR for secondary sarcoma. The risk is one magnitude smaller than for secondary cancer. It is very similar for all techniques. There is nearly no difference between FB and FFF.

The EAR for secondary cancer in the periphery (thyroid and esophagus) has been derived directly from the PD measurements. In both organs we took the point dose as representative for the whole organ for our calculations as a simple approach. Sample measurements for the non-coplanar techniques resulted in much higher doses with factors from 6 to over 100 and were aborted.

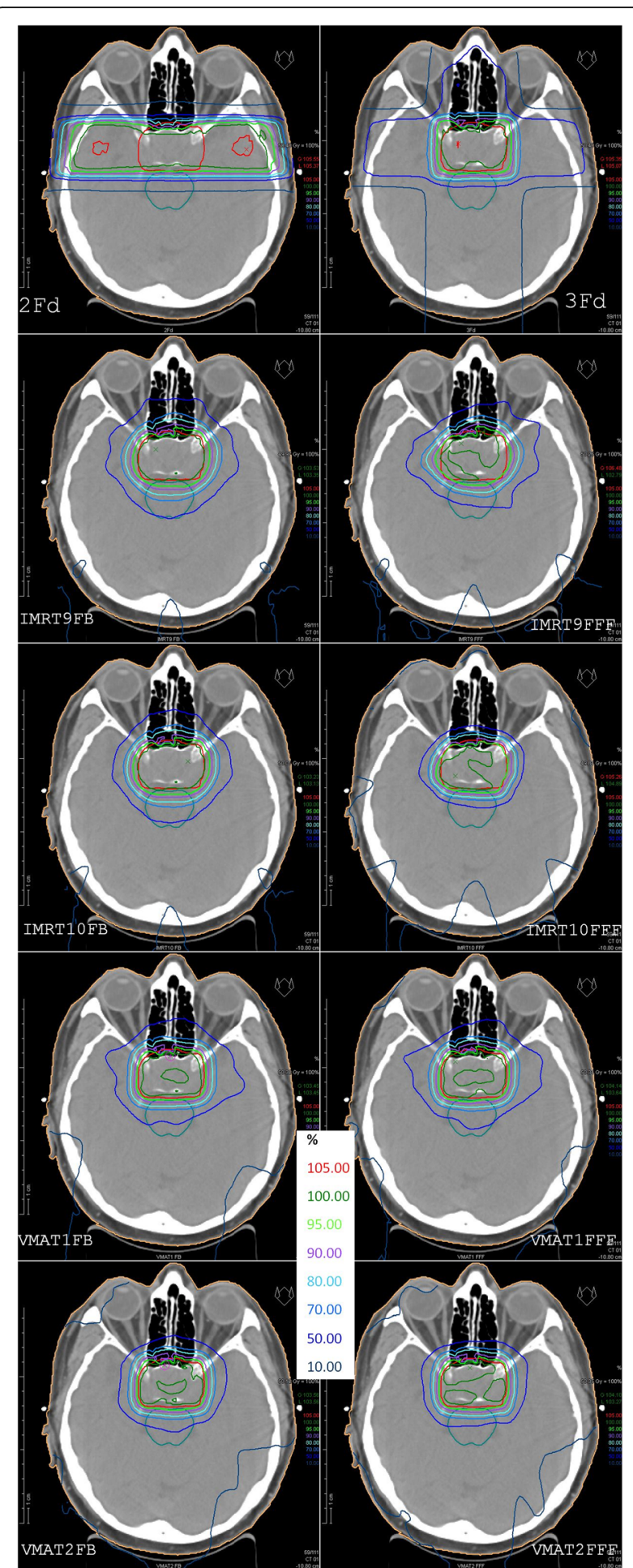

Fig. 3 Isodose distributions in the isocenter plane for one representative patient. The first row shows the classical 2 and 3 field techniques, below in the left column plans with FB mode, in the right column the FFF plans. From 2nd row to bottom: coplanar IMRT, non-coplanar IMRT, coplanar VMAT, non-coplanar VMAT. PTV in red and brain stem in cyan are made visible 

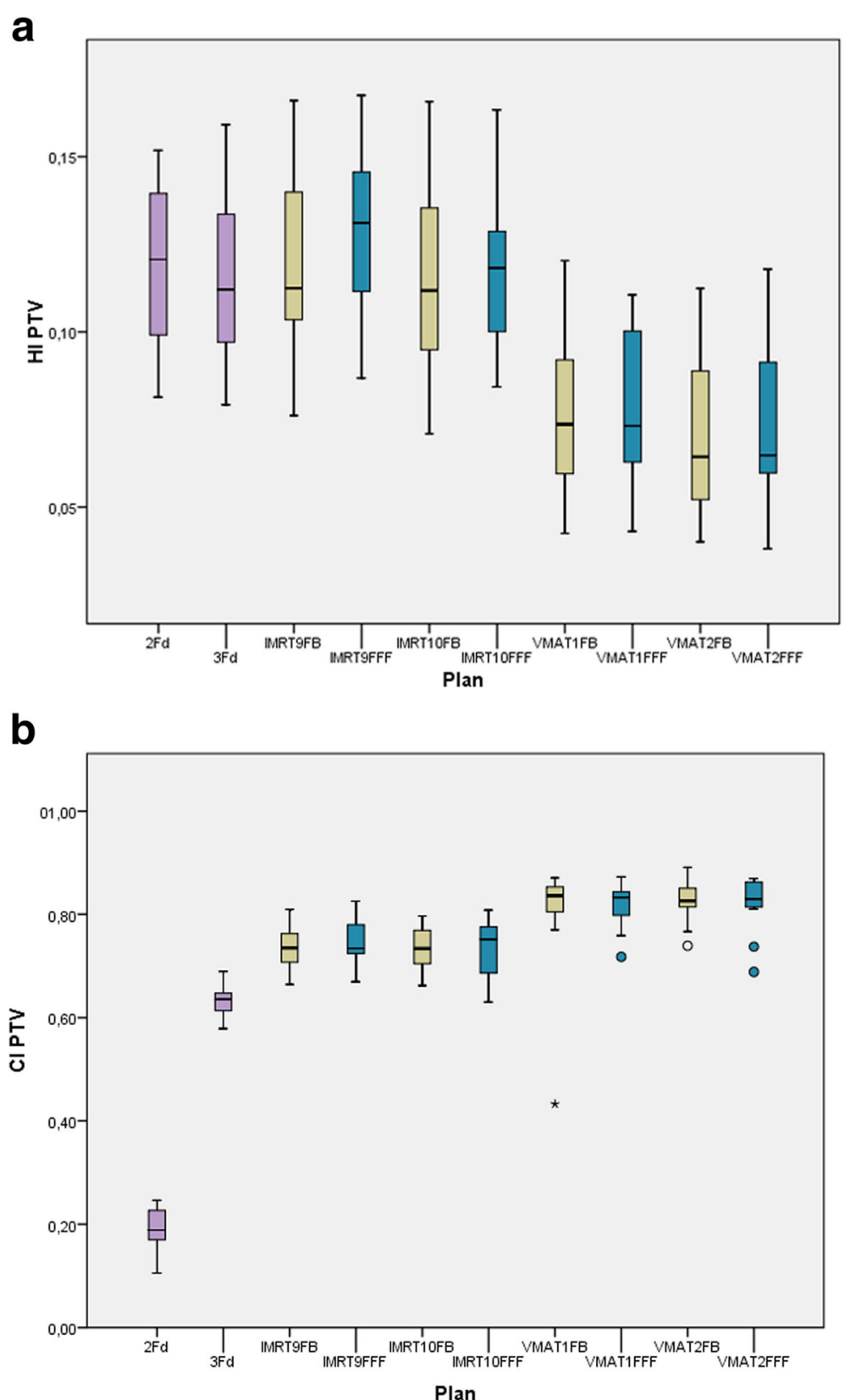

Fig. $4 \mathrm{HI}$ (above) and Cl (below) as boxplots for all plans: The boxes indicate the inner quartiles, the whiskers the outer quartiles. Outliers and extreme values are indicated by circles and asterisks

The EAR at the esophagus was one magnitude smaller than at the thyroid. For the sake of simplicity we added up both values. The corresponding boxplots are given in Fig. 8 . The risk has been reduced statistically significant by the application of FFF mode. VMAT caused the lowest dose and therefore the lowest risk of all techniques.

\section{Plan verification}

The previous results of the plan quality and the secondary malignancy risk demonstrated no benefit for the non-coplanar techniques. Therefore, we verified the coplanar plans only. All plans except of one IMRT plan fulfilled the gamma value acceptance criteria. That means that $95 \%$ of the pixels were within the tolerance level mentioned in the material and methods section.

\section{Discussion}

Plan quality

No rescaling of the dose to the PTV has been performed after the optimization as described in the section material 


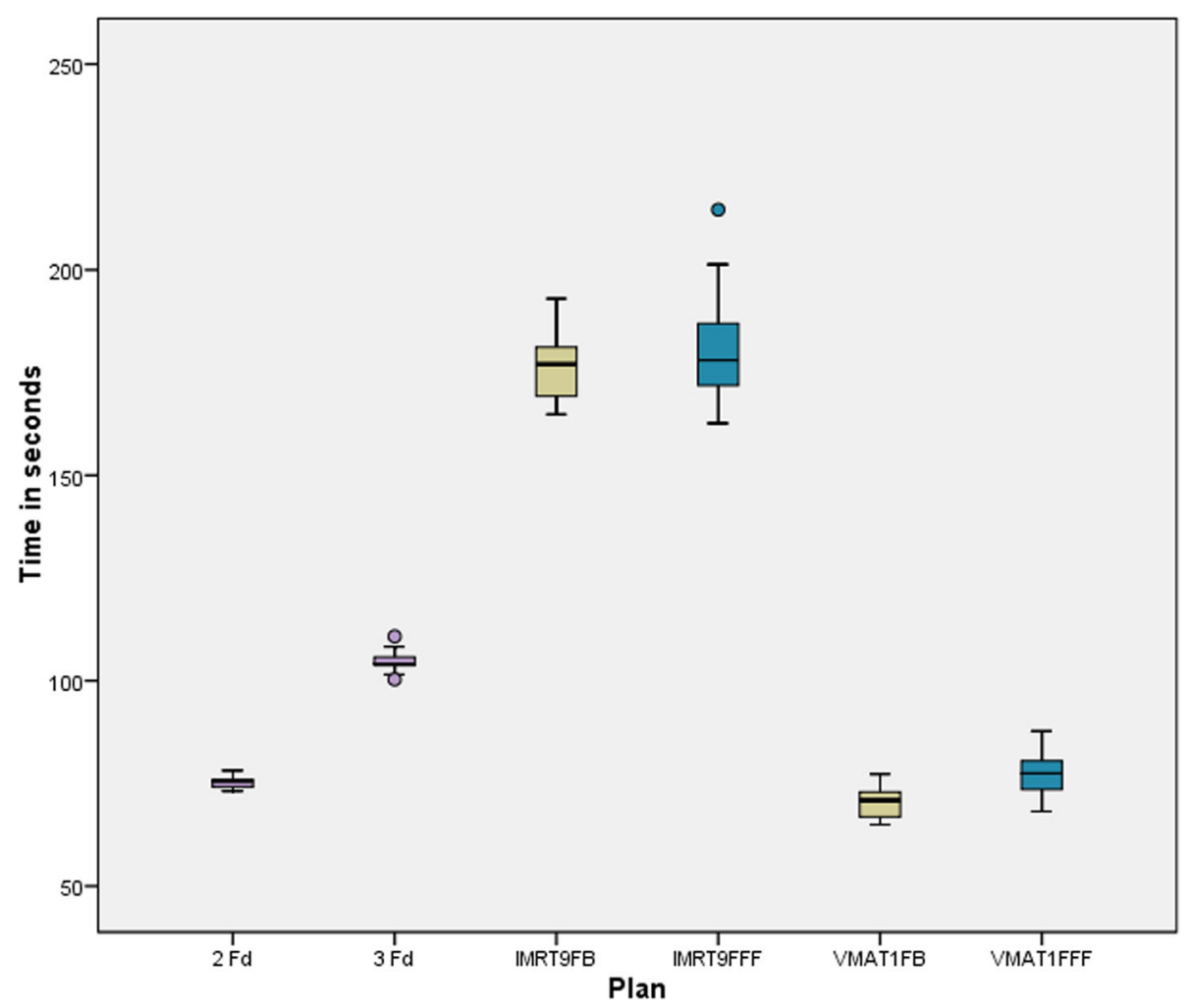

Fig. 5 Delivery time for the different plan groups from pressing the start button to the last beam off

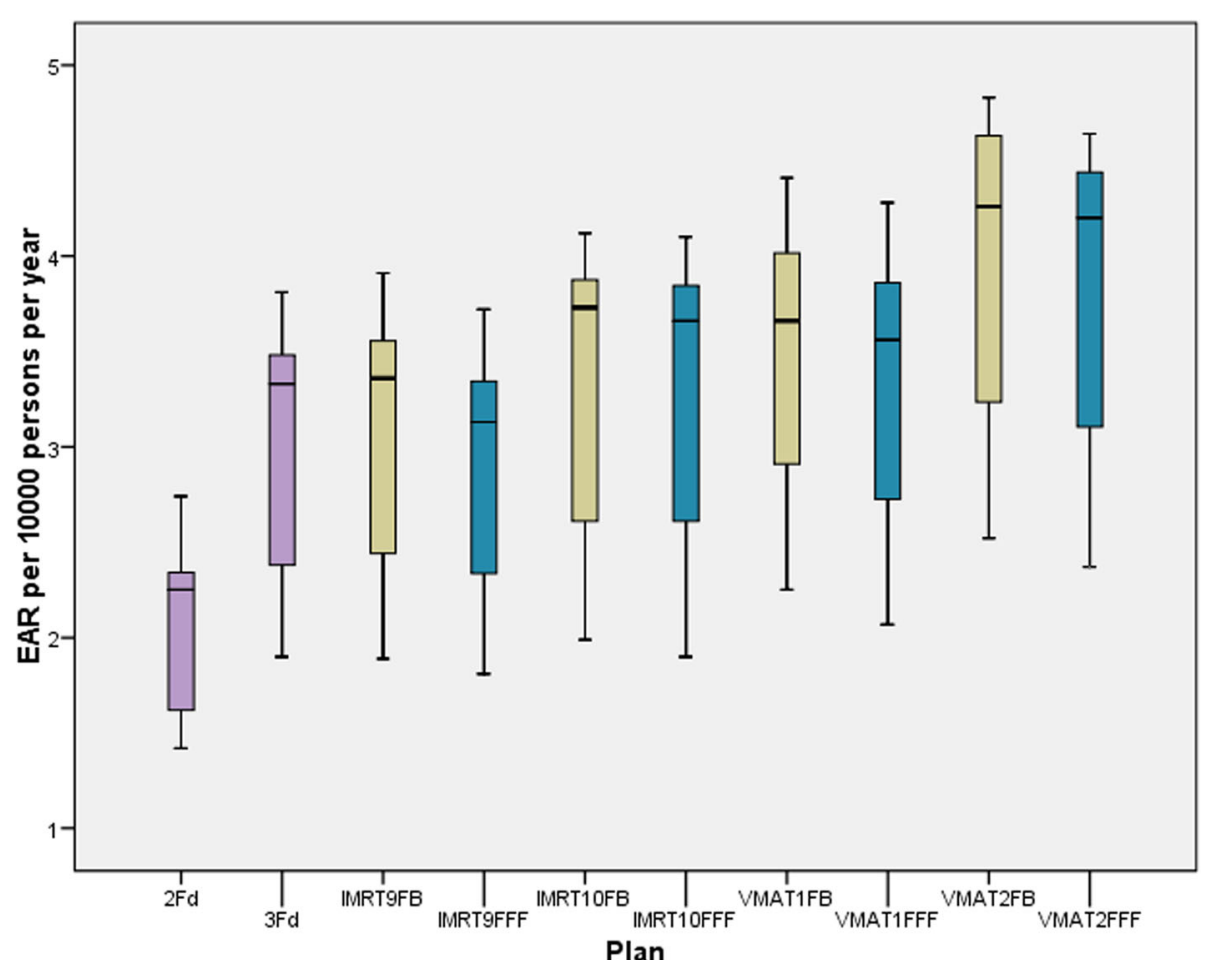

Fig. 6 EAR for secondary brain cancer calculated by the mechanistic model, dependent on the different techniques. FFF (blue) is statistically significant lower than FB (yellow) 

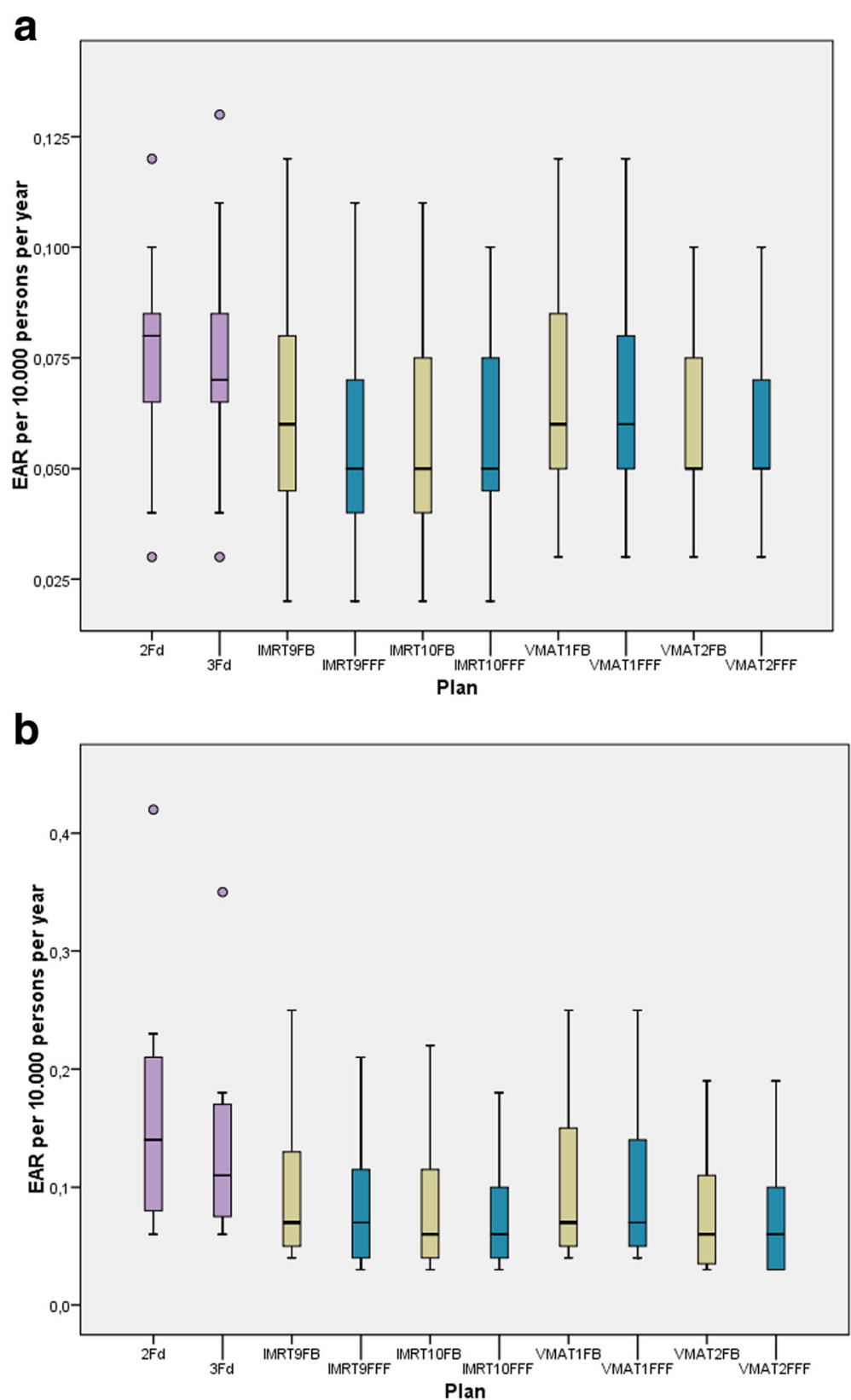

Fig. 7 a. EAR for secondary bone sarcoma dependent on the different techniques. b. EAR for secondary sarcoma of soft tissue dependent on the different techniques

and methods. The failure of reaching the required dose interval for the PTV of one plan could easily be corrected in clinical routine by a rescaling of the MU. The remaining treatment plan objectives would also have been observed after rescaling, except of the chiasm. Choosing other weights for the corresponding objectives of PTV and chiasm might have avoided this little deviation but would probably have impaired the values for $\mathrm{HI}$ and $\mathrm{CI}$. Goldsmith et al. [48] assume a tolerance dose of 54 Gy for radiation-induced optic neuropathy when applied in fractions of $1.8 \mathrm{~Gy}$. Therefore, our values were found acceptable. An improved CI is an indicator of a conformal high dose area and therefore of reduced risk for adverse reactions in the organs at risk and unspecified tissue.

Consideration and observance of the dose volume objectives is a main criterion for the clinical acceptability of a treatment plan. The dose limits were taken from published recommendations and resulting risks for the patient were regarded tolerable. No further ranking has been derived from actually achieved mean dose values below the limits. However, in individual cases, e.g. pretreated patients, further dose reduction in a selected 


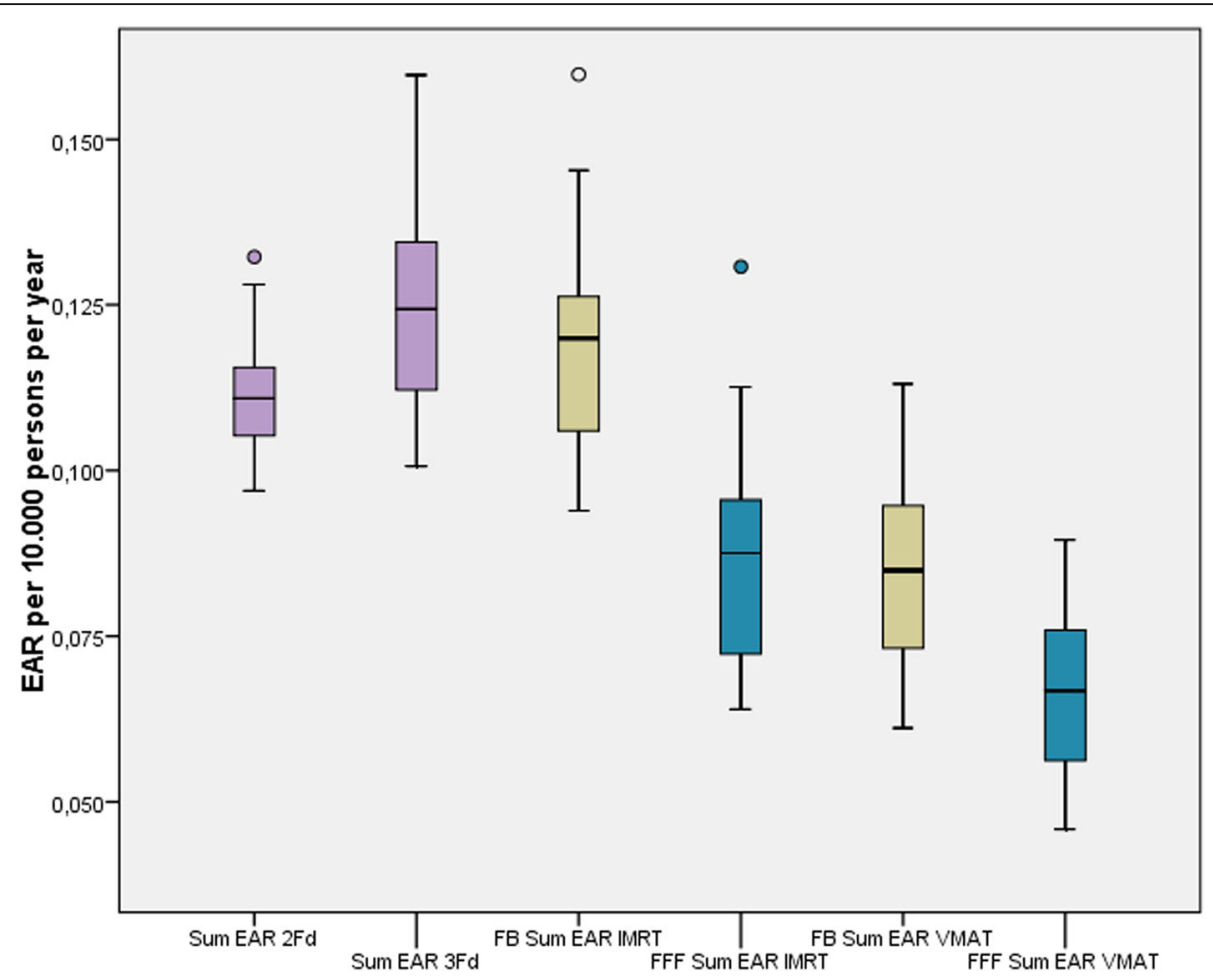

Fig. 8 Summed EAR for secondary carcinoma at the peripheral organs thyroid and esophagus. FFF (blue) is statistically significant lower than FB (yellow)

organ at risk might be accomplished by another treatment technique, setting, or mode.

The results regarding the plan quality cannot simply be generalized to other equipment or tumors. Dobler et al. found no difference in the application of IMRT or VMAT, FB or FFF for patients with hypopharynx/larynx carcinoma [15]. Alvarez-Moret et al. stated in their study about pediatric patients with ependymoma comparable $\mathrm{HI}$ and CI for VMAT FB and FFF, but IMRT FFF superior to IMRT FB [12]. Similarly were the results in an investigation about patients with localized prostate cancer [18].

The $2 \mathrm{Fd}$ and $3 \mathrm{Fd}$ plans were generated using a $5 \mathrm{~mm}$ margin around the PTV. A larger margin probably would improve the $\mathrm{HI}$ but also decrease the $\mathrm{CI}$ and increase the volume of high dose to unspecified tissue and organs at risk.

The reduction of delivery time in the application of VMAT compared to IMRT was also found in the same order for other entities [12, 18, 49], using the same equipment. Most comparisons of FB and FFF in these studies and also [29] found shorter or statistically not significantly different DTs for FFF. Treutwein et al. [18] discussed that additional MU are required to compensate the profile fall off which also takes additional time. And the potential higher dose rate cannot be exploited between all control points, because the gantry speed and also the speed of the collimating elements are limiting factors [15]. In the present case these influences lead to a slight increase in the DT which is of no clinical importance. This result confirms that findings for other entities cannot simply be transferred to all applications. This has also been stated by Dobler et al. [15] who could not confirm all advantages found for the re-irradiation of spinal column metastasis [49] in their study about the treatment of hypopharynx and larynx carcinoma with the same equipment.

It might be surprising that VMAT can compete with 2Fd technique regarding the DT. However, there is one switching off and on the beam less and there is no inactive rotation time needed.

\section{Secondary malignancy risk}

Schneider et al. [40] presented plots of the EAR as a function of the dose. The plot for the brain and central nervous system shows all three models close together. Although these plots end at a maximum dose of $40 \mathrm{~Gy}$, it seems natural that our results which are based on this study, have also similar results for the three models. Fractionation and recovery show only little influence in the EAR. On the other hand there seems to be a dependency on the irradiated volume. The risk increases from 2Fd over 3Fd, IMRT9, up to the non-coplanar VMAT2 technique. 
The excess risk of sarcoma has been found one magnitude smaller than for carcinoma. This is in accordance to the data of Preston et al. [41] of the A-bomb survivors. Schneider et al. [40] concluded from data of radiotherapy patients that the risk might be at comparable magnitude for therapeutic doses. This has not been confirmed for our conditions.

It has been described in the background section that other researchers found reduced PD when applying FFF instead of FB which has been explicated by the missing photon scatter from the flatness filter. Most of these works confined to the documentation of the measured dose. In the present work we calculated the resulting EAR. To our knowledge, similar calculations have only been performed by Murray et al. [17] for a small sample of three patients with early prostate cancer and Alvarez-Moret et al. [12] in a study of pediatric patients with ependymoma. Both confirmed a slightly lower EAR for FFF. The difference between FB and FFF in our study is statistically significant. However, comparing the scales in Figs. 6 and 8 we find the risk at the periphery some magnitude smaller than in the treated region. The magnitude of this ratio is in accordance with the outcomes of Murray et al.

The calculated risks are based on mathematical models and are not directly derived from clinical results. Furthermore, they represent only a part of the risks to which patients with pituitary adenomas are exposed in radiotherapy. Therefore, our results can only support a decision for a specific technique but other factors must be considered.

\section{Plan verification}

The successful plan verifications show that there is no technical problem in the application of FB and FFF, IMRT and VMAT plans. This will probably also be true for the non-coplanar techniques. A hybrid plan verification with original couch angles would not have been possible with our equipment: To avoid the irradiation of the array electronics the patient table could not have been turned to the original angle. As we could not demonstrate any benefit for non-coplanar plans for our standard setup we passed on their verification. However, in individual cases, e.g. pretreated persons, their application can be reasonable.

\section{Conclusion}

It has been shown that in the treatment of pituitary adenomas plans which use the FFF mode are of equal quality as FB plans regarding the homogeneity, the conformity, and the dose to the organs at risk. FFF plans are superior in the respect of secondary malignancy induction. VMAT is the fastest advanced technique, on the same level as opposing fields. Non-coplanar techniques showed no benefit for the investigated parameters but need much more time for couch rotation. Opposing fields cause the lowest secondary brain cancer risk but have the lowest conformity.

For most patients we regard VMAT the better choice than IMRT due to slightly improved $\mathrm{HI}$ and $\mathrm{CI}$ and clearly shortened treatment times. We regard the risk for secondary malignancies as a minor effect which is of the same magnitude for all techniques and modes. However, it can be used as a subordinated criterion with reduced risk using FFF. Taking all results into account coplanar VMAT FFF seems the most preferable technique for the treatment of pituitary adenomas with the given equipment.

\section{Abbreviations \\ 2Fd: Two opposing fields; 3Fd: Three field technique; Cl: Conformity index; CTV: Clinical target volume; DT: Delivery time; EAR: Excess absolute risk; \\ FB: Flattened beam (with flatness filter); FFF: Flattness filter free; GTV : Gross target volume; HI: Homogeneity index; IMRT: Intensity modulated radiotherapy; MU: Monitor units; PD: Peripheral dose; PTV: Planning target volume; RED: Risk equivalent dose; VMAT: Volumetric modulated arc therapy}

\section{Acknowledgements}

SunNuclear Corporation provided phantom, array and software for the plan verification.

\section{Availability of data and material}

The datasets used and/or analysed during the current study are available from the corresponding author on reasonable request.

\section{Authors' contributions}

MT, OK, and BD developed the concept of the study. MT performed the RTPS planning, the measurements, and the evaluation and drafted the manuscript. FS selected the patients, contoured the regions of interest, was responsible for the clinical evaluation of the treatment plans, and drafted the patients section in material and methods. RL developed the software for the calculation of secondary malignancy risk. OK and BD helped to draft the manuscript. All authors read and approved the final manuscript.

\section{Funding}

This study was funded by the Bavarian State Ministry of the Environment and Consumer Protection. The funder did not influence the design of the study, the collection, analysis and interpretation of the data, nor writing the manuscript.

\section{Ethics approval and consent to participate}

Written informed consent was gained from the patients. The survey was approved by the Ethical Committee of the University of Regensburg.

\section{Consent for publication}

Not applicable.

\section{Competing interests}

The authors declare that they have no competing interests.

\section{Author details}

${ }^{1}$ Department for radiotherapy, Regensburg University Medical Center, Regensburg, Germany. ' Faculty of computer science and mathematics, Ostbayerische Technische Hochschule, Regensburg, Germany.

Received: 10 July 2019 Accepted: 13 January 2020

Published online: 03 February 2020

\section{References}

1. van den Bergh ACM, van den Berg G, Schoorl MA, Sluiter WJ, van der Vliet AM, Hoving EW, et al. Immediate postoperative radiotherapy in residual nonfunctioning pituitary adenoma: beneficial effect on local control without additional negative impact on pituitary function and life expectancy. Int J 
Radiat Oncol Biol Phys. 2007;67:863-9. https://doi.org/10.1016/j.jijobp.2006 09.049.

2. Erridge SC, Conkey DS, Stockton D, Strachan MWJ, Statham PFX, Whittle IR, et al. Radiotherapy for pituitary adenomas: long-term efficacy and toxicity. Radiother Oncol. 2009;93:597-601. https://doi.org/10.1016/.j.radonc.2009.09.011

3. Estrada J, Boronat M, Mielgo M, Magallon R, Millan I, Diez S, et al. The longterm outcome of pituitary irradiation after unsuccessful transsphenoidal surgery in Cushing's disease. N Engl J Med. 1997;336:172-7. https:/doi.org/ 10.1056/NEJM199701163360303.

4. Jallad RS, Musolino NR, Salgado LR, Bronstein MD. Treatment of acromegaly: is there still a place for radiotherapy? Pituitary. 2007;10:53-9. https://doi.org/ 10.1007/s11102-007-0002-5.

5. Jenkins PJ, Bates P, Carson MN, Stewart PM, Wass JAH. Conventional pituitary irradiation is effective in lowering serum growth hormone and insulin-like growth factor-l in patients with acromegaly. J Clin Endocrinol Metab. 2006;91:1239-45. https://doi.org/10.1210/jc.2005-1616.

6. Minniti G, Osti M, Jaffrain-Rea ML, Esposito V, Cantore G, Maurizi ER. Long-term follow-up results of postoperative radiation therapy for Cushing's disease. J Neuro-Oncol. 2007;84:79-84. https://doi.org/10.1007/s11060-007-9344-0.

7. Snead FE, Amdur RJ, Morris CG, Mendenhall WM. Long-term outcomes of radiotherapy for pituitary adenomas. Int J Radiat Oncol Biol Phys. 2008;71: 994-8. https://doi.org/10.1016/j.jijobp.2007.11.057.

8. Chae S-M, Lee KW, Son SH. Dosimetric impact of multileaf collimator leaf width according to sophisticated grade of technique in the IMRT and VMAT planning for pituitary adenoma lesion. Oncotarget. 2016;7:78119-26. https:// doi.org/10.18632/oncotarget.12974.

9. Lamiman K, Wong KK, Tamrazi B, Nosrati JD, Olch A, Chang EL, Kiehna EN. A quantitative analysis of craniopharyngioma cyst expansion during and after radiation therapy and surgical implications. Neurosurg Focus. 2016;41:E15. https://doi.org/10.3171/2016.9.FOCUS16298.

10. Minniti G, Osti MF, Niyazi M. Target delineation and optimal radiosurgical dose for pituitary tumors. Radiat Oncol. 2016;11:1-14. https://doi.org/10. 1186/s13014-016-0710-y.

11. Georg D, Knöös T, McClean B. Current status and future perspective of flattening filter free photon beams. Med Phys. 2011;38:1280-93. https://doi. org/10.1118/1.3554643

12. Alvarez Moret J, Obermeier T, Pohl F, Loeschel R, Koelbl O, Dobler B. Second cancer risk after radiation therapy of ependymoma using the flattening filter free irradiation mode of a linear accelerator. J Appl Clin Med Phys. 2018;19: 632-9. https://doi.org/10.1002/acm2.12438.

13. Bell K, Dzierma Y, Palm J, Nuesken F, Licht N, Rube C. mARC prostate treatment planning with Varian eclipse for flat vs. FFF beams Phys Med. 2016;32:474-8. https://doi.org/10.1016/j.jmp.2016.02.011.

14. Dobler B, Maier J, Knott B, Maerz M, Loeschel R, Koelbl O. Second cancer risk after simultaneous integrated boost radiation therapy of right sided breast cancer with and without flattening filter. Strahlenther Onkol. 2016. https://doi.org/10.1007/s00066-016-1025-5.

15. Dobler B, Obermeier T, Hautmann MG, Khemissi A, Koelbl O. Simultaneous integrated boost therapy of carcinoma of the hypopharynx/larynx with and without flattening filter - a treatment planning and dosimetry study. Radiat Oncol. 2017;12:114. https://doi.org/10.1186/s13014-017-0850-8.

16. Maier J, Knott B, Maerz M, Loeschel R, Koelbl O, Dobler B. Simultaneous integrated boost (SIB) radiation therapy of right sided breast cancer with and without flattening filter - a treatment planning study. Radiat Oncol. 2016;11:111. https://doi.org/10.1186/s13014-016-0687-6.

17. Murray LJ, Thompson CM, Lilley J, Cosgrove V, Franks K, Sebag-Montefiore $D$, Henry AM. Radiation-induced second primary cancer risks from modern external beam radiotherapy for early prostate cancer: impact of stereotactic ablative radiotherapy (SABR), volumetric modulated arc therapy (VMAT) and flattening filter free (FFF) radiotherapy. Phys Med Biol. 2015;60:1237-57. https://doi.org/10.1088/0031-9155/60/3/1237.

18. Treutwein M, Hipp M, Koelbl O, Dobler B. Volumetric-modulated arc therapy and intensity-modulated radiation therapy treatment planning for prostate cancer with flattened beam and flattening filter free linear accelerators. J Appl Clin Med Phys. 2017;18:307-14. https://doi.org/10.1002/acm2.12168.

19. Petersenn S, Lüdecke DK, Fahlbusch R, Renner U, Buchfelder M, Wowra B, Saeger W. Therapie von Hypophysentumoren. Dtsch Arztebl Int. 2006; 103:A-474.

20. McDowell BD, Wallace RB, Carnahan RM, Chrischilles EA, Lynch CF, Schlechte JA. Demographic differences in incidence for pituitary adenoma. Pituitary. 2011;14:23-30. https://doi.org/10.1007/s11102-010-0253-4.
21. Paynter D, Weston SJ, Cosgrove VP, Evans JA, Thwaites DI. Beam characteristics of energy-matched flattening filter free beams. Med Phys. 2014;41:52103. https://doi.org/10.1118/1.4871615.

22. Treutwein M, Härtl PM, Gröger C, Katsilieri Z, Dobler B. Linac twins in radiotherapy. In: Nenoi M, editor. Evolution of: Ionizing Radiation Research. London: InTech; 2015. https://doi.org/10.5772/60427.

23. Treutwein M, Hipp M, Kölbl O, Bogner L. IMRT of prostate cancer. Strahlenther Onkol. 2009;185:379-83. https://doi.org/10.1007/s00066-009-1950-7.

24. Morales-Paliza MA, Coffey CW, Ding GX. Evaluation of the dynamic conformal arc therapy in comparison to intensity-modulated radiation therapy in prostate, brain, head-and-neck and spine tumors. J Appl Clin Med Phys. 2011;12:5-19.

25. RTOG. RTOG | Clinical Trials | Study Number 0225. https://www.rtog.org/ ClinicalTrials/ProtocolTable/StudyDetails.aspx?study=0225. Accessed 6 Nov 2018.

26. Scoccianti S, Detti B, Gadda D, Greto D, Furfaro I, Meacci F, et al. Organs at risk in the brain and their dose-constraints in adults and in children: a radiation oncologist's quide for delineation in everyday practice. Radiother Oncol. 2015;114:230-8. https://doi.org/10.1016/j.radonc.2015.01.016.

27. Treutwein M, Hipp M, Kölbl O, Dobler B. Ein neuer Typ von Dose-VolumeObjectives bei der VMAT-Planung von Patienten mit Prostatakarzinom: Surrounding Dose Fall-Off. In: Georg D, editor. Wien; 2011. p. 126-127.

28. Bzdusek K, Friberger H, Eriksson K, Hardemark B, Robinson D, Kaus M. Development and evaluation of an efficient approach to volumetric arc therapy planning. Med Phys. 2009;36:2328-39. https://doi.org/10.1118/1.3132234.

29. Sun W-Z, Chen L, Yang X, Wang B, Deng X-W, Huang X-Y. Comparison of treatment plan quality of VMAT for esophageal carcinoma with: flattening filter beam versus flattening filter free beam. J Cancer. 2018;9:3263-8. https://doi.org/10.7150/jca.26044.

30. ICRU. Prescribing, recording, and reporting photon-beam intensitymodulated radiation therapy (IMRT): contents. J ICRU. 2010;10:1-106.

31. Williams G, Tobler M, Leavitt D. Pitfalls in normalization for intensitymodulated radiation therapy planning. Med Dosim. 2005;30:194-200. https://doi.org/10.1016/j.meddos.2005.06.003.

32. Paddick I. A simple scoring ratio to index the conformity of radiosurgical treatment plans. Technical note. J Neurosurg. 2000;93(Suppl 3):219-22. https://doi.org/10.3171/jns.2000.93.supplement.

33. Kragl G, Baier F, Lutz S, Albrich D, Dalaryd M, Kroupa B, et al. Flattening filter free beams in SBRT and IMRT: dosimetric assessment of peripheral doses. Z Med Phys. 2011;21:91-101. https://doi.org/10.1016/j.zemedi.2010.07.003.

34. Sarkar V, Huang L, Huang Y-HJ, Szegedi MW, Rassiah-Szegedi P, Zhao H, Salter BJ. Head to head comparison of two commercial phantoms used for SRS QA. J Radiosurgery and SBRT. 2016;4:213-23.

35. Bogner L, Scherer J, Treutwein M, Hartmann M, Gum F, Amediek A. Verification of IMRT: techniques and problems. Strahlenther Onkol. 2004;180: 340-50. https://doi.org/10.1007/s00066-004-1219-0.

36. Dobler B, Streck N, Klein E, Loeschel R, Haertl P, Koelbl O. Hybrid plan verification for intensity-modulated radiation therapy (IMRT) using the $2 \mathrm{D}$ ionization chamber array I'mRT MatriXX - a feasability study. Phys Med Biol. 2010:55:N39-55.

37. van Esch A, Basta K, Evrard M, Ghislain M, Sergent F, Huyskens DP. The Octavius $15002 \mathrm{D}$ ion chamber array and its associated phantoms: Dosimetric characterization of a new prototype. Med Phys. 2014;41:91708. https://doi.org/10.1118/1.4892178.

38. Low DA, Harms WB, Mutic S, Purdy JA. A technique for the quantitative evaluation of dose distributions. Med Phys. 1998;25:656-61. https://doi.org/ 10.1118/1.598248

39. Ezzell GA, Burmeister JW, Dogan N, LoSasso TJ, Mechalakos JG, Mihailidis D, et al. IMRT commissioning: multiple institution planning and dosimetry comparisons, a report from AAPM task group 119. Med Phys. 2009;36:535973. https://doi.org/10.1118/1.3238104.

40. Schneider U, Sumila M, Robotka J. Site-specific dose-response relationships for cancer induction from the combined Japanese A-bomb and Hodgkin cohorts for doses relevant to radiotherapy. Theor Biol Med Model. 2011;8:127. https://doi.org/10.1186/1742-4682-8-27.

41. Preston DL, Ron E, Tokuoka S, Funamoto S, Nishi N, Soda M, et al. Solid cancer incidence in atomic bomb survivors: 1958-1998. Radiat Res. 2007;168: 1-64. https://doi.org/10.1667/RR0763.1.

42. Dores GM, Metayer C, Curtis RE, Lynch CF, Clarke EA, Glimelius B, et al. Second malignant neoplasms among long-term survivors of Hodgkin's disease: a population-based evaluation over 25 years. J Clin Oncol. 2002;20: 3484-94. https://doi.org/10.1200/JCO.2002.09.038. 
43. Yamanaka R, Abe E, Sato T, Hayano A, Takashima Y. Secondary intracranial tumors following radiotherapy for pituitary adenomas: a systematic review. Cancers (Basel). 2017. https://doi.org/10.3390/cancers9080103.

44. Jiang $X$, Liu Z, Huang $X$, Wang H, Zhao H. Extended endoscopic endonasal approach for pituitary adenoma: a single-center experience of 171 patients. Chin Neurosurg Jl. 2017;3:613. https://doi.org/10.1186/s41016-017-0080-9.

45. Faul F, Erdfelder E, Lang A-G, Buchner A. G* power 3: a flexible statistical power analysis program for the social, behavioral, and biomedical sciences. Behav Res Methods. 2007;39:175-91. https://doi.org/10.3758/BF03193146.

46. Faul F, Erdfelder E, Buchner A, Lang A-G. Statistical power analyses using $G^{*}$ power 3.1: tests for correlation and regression analyses. Behav Res Methods. 2009:41:1149-60. https://doi.org/10.3758/BRM.41.4.1149.

47. Bender R, Lange S. Adjusting for multiple testing--when and how? J Clin Epidemiol. 2001;54:343-9.

48. Goldsmith BJ, Rosenthal SA, Wara WM, Larson DA. Optic neuropathy after irradiation of meningioma. Radiology. 1992;185:71-6. https://doi.org/10. 1148/radiology.185.1.1523337.

49. Dobler B, Khemissi A, Obermeier T, Hautmann MG, Katsilieri Z, Kölbl O. Reirradiating spinal column metastases using IMRT and VMAT with and without flattening filter - a treatment planning study. Radiat Oncol. 2016;11: 1280. https://doi.org/10.1186/s13014-016-0603-0.

\section{Publisher's Note}

Springer Nature remains neutral with regard to jurisdictional claims in published maps and institutional affiliations.

Ready to submit your research? Choose BMC and benefit from:

- fast, convenient online submission

- thorough peer review by experienced researchers in your field

- rapid publication on acceptance

- support for research data, including large and complex data types

- gold Open Access which fosters wider collaboration and increased citations

- maximum visibility for your research: over $100 \mathrm{M}$ website views per year

At $\mathrm{BMC}$, research is always in progress.

Learn more biomedcentral.com/submissions 